\title{
A case of presumed post-traumatic pneumocephalus
}

\author{
Varo Kirthi, ${ }^{1}$ Aniket N Tavare, ${ }^{2}$ Jeremy Hoffman, ${ }^{3}$ Lucia Pelosini $^{1}$
}

${ }^{1}$ Department of

Ophthalmology, East Surrey Hospital, Redhill, Surrey, UK ${ }^{2}$ Department of Radiology, Royal Free London NHS Foundation Trust, London, UK ${ }^{3}$ Department of Ophthalmology, Surrey and Sussex Healthcare NHS Trust, Redhill, UK

\section{Correspondence to}

Dr Varo Kirthi,

varo.kirthi@gmail.com

Accepted 15 October 2015

\section{DESCRIPTION}

Intracranial fat deposits are uncommon benign lesions and are usually incidental findings when the brain is imaged for other reasons. Spontaneous or traumatic dermoid cyst rupture is the putative underlying cause in most cases. ${ }^{1}$

We describe a case of a 71-year-old woman, who presented 10 days after a fall at home, reporting occipital pain and acute-onset vertical diplopia. On examination, there was no external bruising, but a left trochlear nerve palsy was clinically elicited.

CT scan was reported as "no evidence of orbital/ skull fracture or haemorrhage, but widespread hypodense foci in keeping with pneumocephalus' (figure 1). Urgent neurosurgical and ophthalmological opinions were sought, and the patient was admitted for observation.

Subsequent MRI showed multiple high-signal foci on T1 and fluid-attenuated inversion recovery consistent with intracerebral fat deposits (figure 2A, B). Spinal MRI confirmed a large ruptured dermoid cyst at L5/S1 as the source of the subarachnoid fat. Careful re-examination of the CT images on lung window confirmed the lesions were not of air density (figure 3 ).

After orthoptic review, the patient was prescribed vertical prismatic lenses, which significantly improved her symptoms. Spontaneous resolution of the diplopia was noted on follow-up at 6 months.

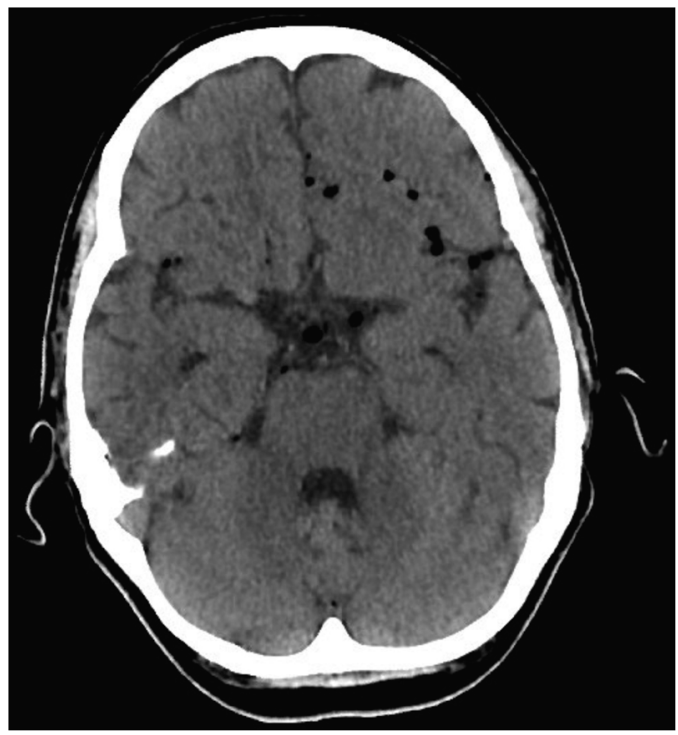

Figure $1 \mathrm{CT}$ of the head showing hypodense foci suggestive of pneumocephalus.
Ruptured intracranial dermoid is a rare but documented cause of headache. ${ }^{2}$ However, traumatic dermoid rupture has only been documented in a handful of cases, and never before in association with an acute cranial nerve palsy without raised intracranial pressure. ${ }^{3}$ In this case, neuroimaging revealed no other underlying cause for the trochlear nerve palsy.
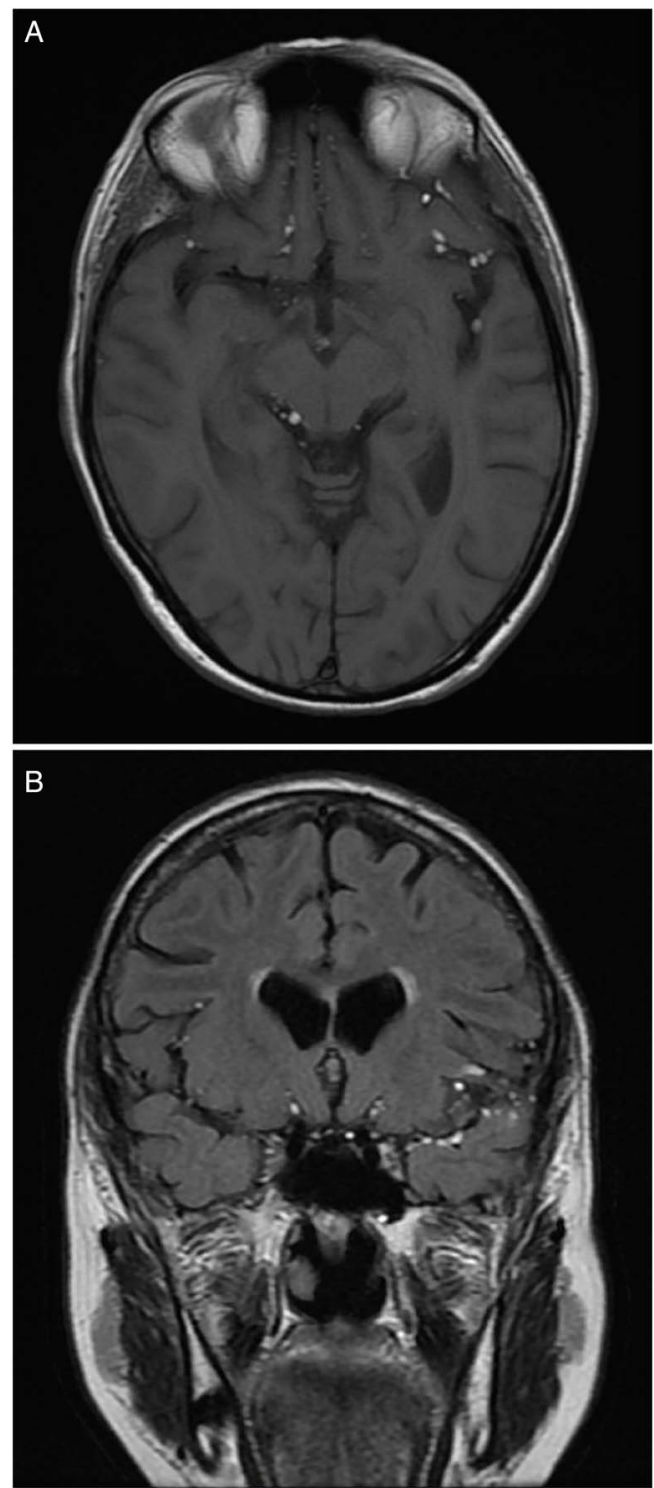

Figure 2 MRI of the head: (A) axial and (B) coronal images showing multiple high-signal lesions in keeping with intracerebral fat in $\mathrm{T} 1$ and fluid-attenuated inversion recovery sequences. 


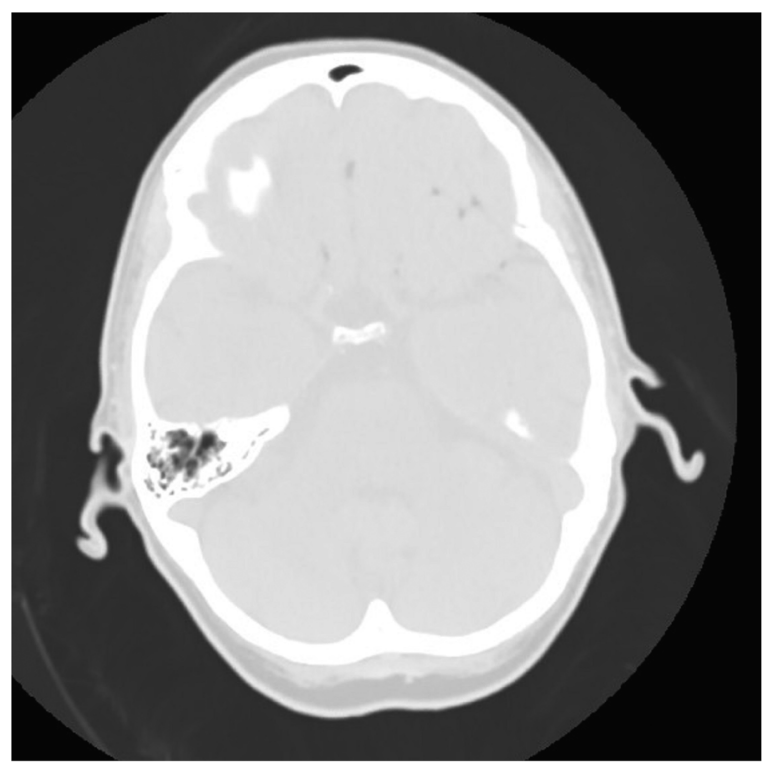

Twitter Follow Jeremy Hoffman at @idoctorhoff

Contributors VK cared for the patient and prepared the first draft of the manuscript. ANT examined and selected the appropriate radiology images and provided input on editing the draft manuscript. JH assisted with image manipulation and reviewed the draft manuscript. LP was the consultant in charge of the patient's care and proof read the final manuscript prior to submission.

Competing interests None declared.

\section{Patient consent Obtained.}

Provenance and peer review Not commissioned; externally peer reviewed.

\section{REFERENCES}

1 Lyo IU, Sim HB, Park JB, et al. Intraventricular and subarachnoid fat after spinal injury. J Korean Neurosurg Soc 2008;44:95-7.

2 Rajapakse A, Diack A. Ruptured intracranial dermoid: an unusual cause of headache in an older patient. Headache 2008;48:294-6.

3 Esquenazi Y, Kerr K, Bhattacharjee MB, et al. Traumatic rupture of an intracranial dermoid cyst: case report and literature review. Surg Neurol Int 2013;4:80.

Figure $3 \mathrm{CT}$ of the head on lung window showing lesion densities not in keeping with air.

\section{Learning points}

- Intracerebral fat deposition is a benign condition, usually an incidental finding on brain imaging.

- Careful attention to signal intensity under the appropriate window settings will ensure that fat deposits are not confused with air on $\mathrm{CT}$ imaging.

- Acute-onset diplopia should always raise suspicion of a cranial nerve injury, even if no lesion can be identified on neuroimaging.

Copyright 2015 BMJ Publishing Group. All rights reserved. For permission to reuse any of this content visit http://group.bmj.com/group/rights-licensing/permissions.

BMJ Case Report Fellows may re-use this article for personal use and teaching without any further permission.

Become a Fellow of BMJ Case Reports today and you can:

- Submit as many cases as you like

- Enjoy fast sympathetic peer review and rapid publication of accepted articles

- Access all the published articles

- Re-use any of the published material for personal use and teaching without further permission

For information on Institutional Fellowships contact consortiasales@bmjgroup.com

Visit casereports.bmj.com for more articles like this and to become a Fellow 